\title{
Genetically defining the mechanism of Puma- and Bim-induced apoptosis
}

\author{
SP Garrison ${ }^{1,4}$, DC Phillips ${ }^{1,4,5}$, JR Jeffers ${ }^{1}$, JE Chipuk ${ }^{2,6}$, MJ Parsons ${ }^{2}$, JE Rehg ${ }^{3}$, JT Opferman ${ }^{1}$, DR Green ${ }^{2}$ and GP Zambetti ${ }^{\star, 1}$
}

Using genetically modified mouse models, we report here that p53 upregulated modulator of apoptosis (Puma) and Bcl-2 interacting mediator of cell death (Bim), two pro-apoptotic members of the B-cell lymphoma protein-2 (Bcl-2) family of proteins, cooperate in causing bone marrow and gastrointestinal tract toxicity in response to chemo and radiation therapy. Deletion of both Puma and Bim provides long-term survival without evidence of increased tumor susceptibility following a lethal challenge of carboplatin and ionizing radiation. Consistent with these in vivo findings, studies of primary mast cells demonstrated that the loss of Puma and Bim confers complete protection from cytokine starvation and DNA damage, similar to that observed for Bax/ Bak double knockout cells. Biochemical analyses demonstrated an essential role for either Puma or Bim to activate Bax, thereby leading to mitochondrial outer membrane permeability, cytochrome $c$ release and apoptosis. Treatment of cytokine-deprived cells with ABT-737, a BH3 mimetic, demonstrated that Puma is sufficient to activate Bax even in the absence of all other known direct activators, including Bim, Bid and p53. Collectively, our results identify Puma and Bim as key mediators of DNA damageinduced bone marrow failure and provide mechanistic insight into how $\mathrm{BH} 3$-only proteins trigger cell death.

Cell Death and Differentiation (2012) 19, 642-649; doi:10.1038/cdd.2011.136; published online 21 October 2011

Programmed cell death, or apoptosis, is an evolutionary conserved process that regulates normal cellular homeostasis, and when deregulated results in developmental malformations, neurodegeneration, cancer and autoimmunity. ${ }^{1}$ The initiation of apoptosis occurs through intrinsic and extrinsic pathways that can converge at the mitochondria. ${ }^{2}$ Cellular stresses trigger mitochondrial outer membrane permeabilization (MOMP) and the release of cytochrome $c$, which complexes with APAF-1 and pro-caspase-9, leading to the activation of the caspase cascade and the eventual dismantling of the cell. ${ }^{3}$

Central to the regulation of MOMP is the B-cell lymphoma protein-2 (Bcl-2) family of proteins. The anti-apoptotic members Bcl-2, Bcl- $\mathrm{X}_{\mathrm{L}}, \mathrm{Bcl}-\mathrm{W}, \mathrm{Mcl}-1$ and $\mathrm{A} 1$ each contain four $\mathrm{BH}$ domains $(\mathrm{BH} 1-4)$, and maintain mitochondrial integrity by inhibiting the pro-apoptotic effectors Bax and Bak, which facilitate the release of cytochrome $c$ into the cytoplasm. The BH3-only pro-apoptotic proteins Bim (Bcl-2 interacting mediator of cell death), Bid, Puma (p53 upregulated modulator of apoptosis), Noxa, Bad, Bik, Bmf and Hrk respond to cell death stimuli, including but not limited to DNA damage, growth factor withdrawal and ER stress. ${ }^{4,5}$ These $\mathrm{BH} 3-$ only proteins can be further subdivided into 'derepressors' (e.g. Bad, Bik and Noxa) that only bind the anti-apoptotic proteins and 'direct activators' (e.g. Bim and Bid) that can also directly trigger the activation of the pro-apoptotic effectors Bax and Bak. ${ }^{6}$ The tumor suppressor p53, which initiates apoptosis through the transcriptional upregulation of Puma, Noxa and other target genes, has also been reported to antagonize $\mathrm{Bcl}-2, \mathrm{Bcl}-\mathrm{X}_{\mathrm{L}}$ and $\mathrm{Mcl}-1$, and to directly activate Bax/Bak. ${ }^{7-9}$ Similarly, Puma may also act as a direct activator of Bax and Bak. ${ }^{10}$

We have taken a genetic and biochemical approach using knockout mice and primary cell lines to test the functional requirements of Puma, Bim, Bid and p53, the only known putative direct activators of Bax and Bak, in the induction of apoptosis. We report here that Puma and Bim cooperate in the activation of Bax/Bak in response to signals that trigger both p53-dependent and p53-independent cell death. Deletion of Puma and Bim protected mice long term without a significant increased risk of cancer from a lethal myelosuppressive regimen of carboplatin and ionizing radiation. Moreover, Puma $^{-1-} /$ Bim $^{-1-}$ double knockout (DKO) primary bone marrow cells expanded in culture remained viable when deprived of growth factors and treated with irradiation (IR) or the BH3-mimetic drug ABT-737. The extent of survival was equivalent to that observed for $\mathrm{Bax}^{-/} / \mathrm{Bak}^{-/-}$cells. By contrast, cells lacking Bim, Bid and p53 either individually or collectively remained sensitive to growth factor deprivation and ABT-737 treatment. Our results demonstrate that the

\footnotetext{
${ }^{1}$ Department of Biochemistry, St. Jude Children's Research Hospital, Memphis, TN 38105, USA; ²Department of Immunology, St. Jude Children's Research Hospital, Memphis, TN 38105, USA and ${ }^{3}$ Department of Pathology, St. Jude Children's Research Hospital, Memphis, TN 38105, USA

*Corresponding author: GP Zambetti, Department of Biochemistry, St. Jude Children's Research Hospital, 262 Danny Thomas Place, Memphis, TN 38105 , USA.

Tel: + 901595 6028; Fax: + 901525 8025; E-mail: gerard.zambetti@stjude.org

${ }^{4}$ These authors contributed equally to this work.

${ }^{5}$ Current address: Cancer Research, Abbott Laboratories, Abbott Park, IL 60064, USA.

${ }^{6}$ Current address: Department of Oncological Sciences, Mount Sinai School of Medicine, New York, NY 10029, USA.

Keywords: Puma; Bim; apoptosis; myelosuppression; ABT-737

Abbreviations: Puma, p53 upregulated modulator of apoptosis; Bim, Bcl-2 interacting mediator of cell death; MOMP, mitochondrial outer membrane permeabilization; IR, irradiation; TPO, thrombopoietin; GI, gastrointestinal; SCF, stem cell factor; MCP, mast cell protease; CTMC, connective tissue mast cell

Received 17.2.11; revised 29.7.11; accepted 08.9.11; Edited by V Dixit; published online 21.10.11
} 
BH3-only protein Puma is sufficient to induce Bax/Bak activation even in the absence of all other known direct activators. Most importantly, our findings provide a proof-ofprinciple that $\mathrm{BH} 3$ antagonists (e.g. small molecule inhibitors) could be developed to alleviate hematological toxicities commonly associated with cancer therapies without significantly increasing the risk of secondary malignancies.

\section{Results}

Cooperation of Puma and Bim in therapy-induced lethal myelosuppression. Previous studies demonstrated that the pathogenicity and mortality associated with the lethal myelosuppressive regimen of carboplatin plus $\gamma$-IR could be circumvented either by the deletion of the tumor suppressor p53 or by the immediate treatment of the mice with recombinant cytokine thrombopoietin (TPO) post-therapy. ${ }^{11}$ p53-deficient mice are presumably resistant to the myelosuppression regimen due to a failure to upregulate pro-apoptotic target genes, such as Puma, or to trigger cell death by directly activating Bax. TPO likely protects the hematopoietic compartment through the upregulation of the pro-survival proteins $\mathrm{Bcl}-2, \mathrm{Bcl}-\mathrm{X}_{\mathrm{L}}$ and $\mathrm{Mcl}-1$, which inhibit apoptosis by preventing Bax/Bak from inducing MOMP. ${ }^{12,13}$ Furthermore, TPO may have a protective role by suppressing the expression of pro-apoptotics, such as Puma and Bim. To begin challenging these hypotheses, wild-type (WT), Puma $^{-1-}$, Bim ${ }^{-1-}$ and Puma ${ }^{-1-} / \mathrm{Bim}^{-1-}$ mice were treated with carboplatin $(80 \mathrm{mg} / \mathrm{kg})$ immediately followed by $7.5 \mathrm{~Gy}$ total body IR and monitored for survival and recovery of hematopoiesis over time (Figure 1). Consistent with previous studies, all WT animals died by day 15 (median survival 12.5 days) due to bacteremia resulting from gastrointestinal (GI) damage, in combination with bone marrow failure (Supplementary Figure 1). Essentially, the damage to the GI tract leads to a breach in the colonic barrier, allowing resident bacteria to escape. Since the combined treatment immunocompromises the mice, they are unable to mount an effective immune response; hence, the animals develop disseminated bacteremia throughout a variety of tissues including the lungs, kidney and heart (Supplementary Figure 1 and data not shown). Similarly, the $\mathrm{Bim}^{-1-}$ mice were also sensitive to colonic damage and myelosuppression and succumbed to bacteremia with a median survival of 13 days. The Puma $^{-/-}$mice were remarkably resistant and
$100 \%$ survived 4 weeks after treatment, most likely due to maintaining Gl tract integrity (Supplementary Figure 1); however, $\sim 40 \%$ of the animals died between days 55 and 77 due to carditis, atherosclerosis, arteriosclerosis and unknown causes. By contrast, Puma ${ }^{-1-} / \mathrm{Bim}^{-1-}$ DKO mice were completely protected and survived long term without significant sequelae or increased tumor susceptibility (Figure 1a) when compared with untreated Puma $^{-/-} / \mathrm{Bim}^{-1-}$ mice, which spontaneously develop lymphomas and sarcomas by $\sim 1$ year of age. ${ }^{14}$

Bone marrow recovery was determined by assaying white blood cells (WBCs), platelets and hemoglobin in peripheral blood every 5 days after treatment (Figure 1b). All animals, regardless of genotype, displayed a sharp decrease in each of these parameters within the first 2 weeks. However, the Puma $^{-1-}$ and Puma $^{-1-} / \mathrm{Bim}^{-1-}$ mice began recovering WBC, platelets and hemoglobin by day 15 , whereas the WT and $\mathrm{Bim}^{-1-}$ mice failed to restore hematopoiesis and died because of an insufficient immune response to bacteremia caused by GI syndrome. These results suggest that loss of Puma alone is adequate for protecting bone marrow progenitors and intestinal cells from DNA damage, and that combined deletion of Puma and Bim is required for long-term survival postchemo and radiation therapy.

Functional redundancy of Puma and Bim in primary myeloid cells. To examine the molecular mechanisms by which Puma and Bim contribute to apoptosis, bone marrow cells derived from WT, Bim ${ }^{-/-}$, Puma $^{-/-}$and Puma ${ }^{-/-}$, $\mathrm{Bim}^{-/-}$mice were expanded in tissue culture in the presence of IL3, IL6 and stem cell factor (SCF) as previously described, resulting in Sca,$+ \quad \mathrm{cKit}+, \mathrm{Lin}-$ cell populations. ${ }^{15,16}$ Detailed phenotype analyses demonstrated that the primary cells express $\mathrm{Fc}_{\varepsilon} \mathrm{R} 1$ and MC-protease-5 (mMCP-5), but not MC-protease-1 (mMCP-1), which is indicative of connective tissue mast cells (CTMCs; Supplementary Figure 2). ${ }^{17}$ Notably, deletion of Bim and/or Puma did not alter differentiation, resulting in the expansion of identical myeloid cell types regardless of genotype. Primary CTMCs require cytokines for proliferation and survival, and during growth factor starvation undergo G1 cell-cycle arrest and apoptosis in a p53-independent manner. Cell death during cytokine deprivation is accelerated by ionizing radiation and other DNA damaging agents, which occurs through a p53-dependent apoptotic mechanism. ${ }^{18}$
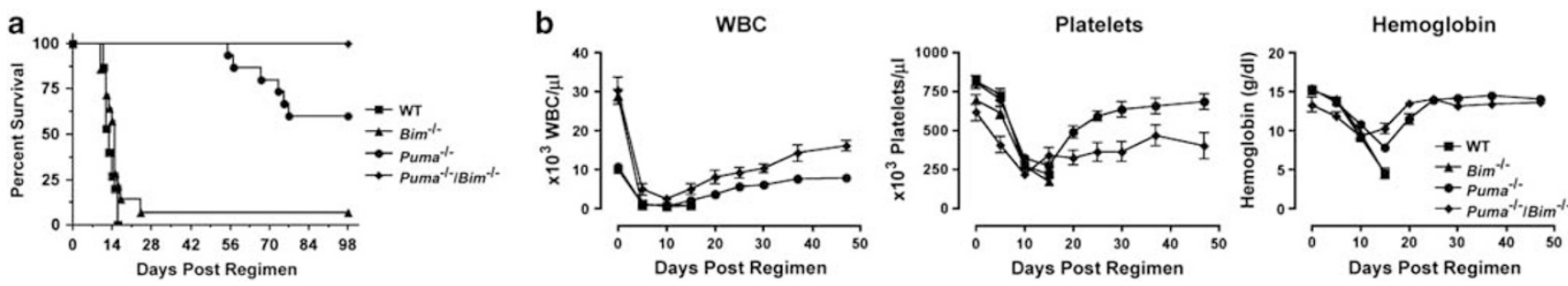

Figure 1 Co-deletion of Bim and Puma protects mice from lethal myelosuppression and is associated with recovery of the hematopoietic system. (a) Survival of wild-type (WT) (squares; $n=15)$, Bim $^{-1-}$ (triangles; $n=14$ ), Puma $^{-1-}$ (circles; $n=15$ ) and Puma ${ }^{-1-} /$ Bim $^{-1-}$ (diamonds; $n=7$ ) mice treated with a myelosuppressive regimen of $80 \mathrm{mg} / \mathrm{kg}$ carboplatin and $7.5 \mathrm{~Gy} \mathrm{TBI}$. (b) The effects of $80 \mathrm{mg} / \mathrm{kg}$ carboplatin and $7.5 \mathrm{~Gy}$ TBI on white blood cell count (WBC; left panel), platelet count (middle panel) and hemoglobin concentration (right panel) in each mouse, from (a), determined at the indicated time points. Each data point in (b) represents the mean \pm S.E.M. 


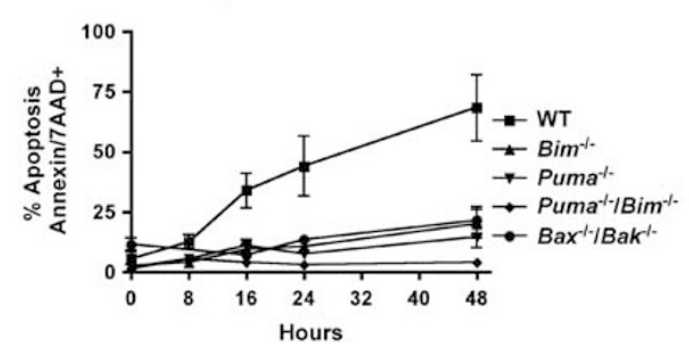

b Cytokine Withdrawal + IR

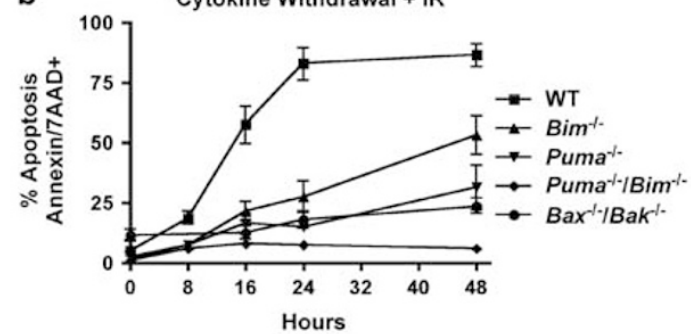

$c$

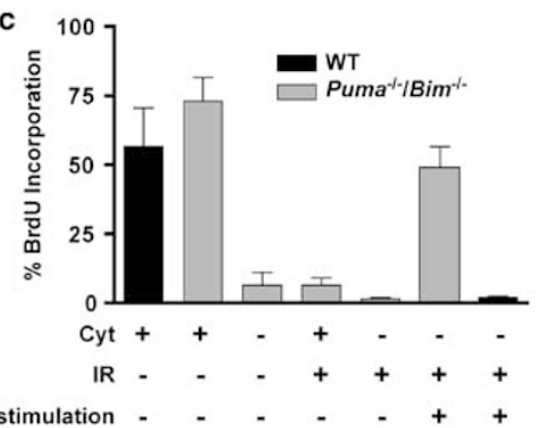

Figure 2 Puma ${ }^{-/-} / \mathrm{Bim}^{-/}$primary CTMCs are resistant to $\mathrm{p53}$-dependent and p53-independent cell death. (a and b) WT (squares), Bim ${ }^{-/}$(triangles), Puma $^{-1-}$ (inverted triangles), Puma ${ }^{-1-} / \mathrm{Bim}^{-1-}$ (diamonds) and conditionally deleted Bax/ Bak double knockout (circles) cells were deprived of cytokines for $0-48 \mathrm{~h} \mathrm{(a)} \mathrm{or} \mathrm{in}$ combination with $5 \mathrm{~Gy} I \mathrm{R}(\mathbf{b})$. Apoptosis was assessed by flow cytometry of AnnexinV/7AAD-positive cells. (c) WT and Puma ${ }^{-1-} / \mathrm{Bim}^{-1}$ cells were cultured in complete media with and without cytokines ( $+/-$ Cyt) for $48 \mathrm{~h}$, treated with $5 \mathrm{~Gy}$ ionizing radiation (IR) at time zero, or restimulated with cytokines for $24 \mathrm{~h}$ following Cyt deprivation with. DNA synthesis was monitored by BrdU incorporation and FACS analysis, and quantified as the percent of BrdU-positive cells. Data are presented as the mean \pm S.E.M. of at least three independent experiments, each performed with bone marrow-derived cells isolated from $(\geq 2)$ mice for each genotype

Consistent with these findings, cytokine deprivation blocked the proliferation and induced the death of primary WT cells (Figure 2a, $P \leq 0.012$ and data not shown), which was markedly enhanced by 5 Gy of ionizing radiation (Figure $2 \mathrm{~b}$, $P \leq 0.006$ ). By contrast, Bim ${ }^{-/}$and Puma $^{-/-}$cells maintained substantial viability for $48 \mathrm{~h}$ during cytokine starvation with and without IR (Figures $2 \mathrm{a}$ and b). Notably, primary Puma ${ }^{-/-} / \mathrm{Bim}^{-1-}$ cells remained fully viable during cytokine starvation, even when treated with IR (Figure 2b), as demonstrated by the resumption of DNA synthesis following cytokine stimulation after $48 \mathrm{~h}$ starvation and IR treatment (Figure 2c). Indeed, the resistance of $\mathrm{Puma}^{-1} / \mathrm{Bim}^{-/}$cells to cytokine withdrawal plus IR was equivalent to conditional $\mathrm{Bax}^{-/-} / \mathrm{Bak}^{-/-}$cells (Figures 2a and b), indicating that Puma and $\mathrm{Bim}$ are functionally redundant and account for essentially all of the apoptotic activity in DNA-damaged primary CTMCs deprived of growth factors.

Bid is dispensable for myeloid apoptosis during growth factor withdrawal and DNA damage. Bid, a pro-apoptotic $\mathrm{BH} 3-$ only protein commonly associated with the extrinsic apoptotic pathway, activates Bax to induce apoptosis. ${ }^{19}$ It has also been reported that the p53 tumor suppressor has a similar role in triggering cell death through Bax activation. ${ }^{7-9}$ To address the role of these putative 'direct activators' in myeloid cell death during cytokine deprivation plus IR, $\mathrm{Bid}^{-1-} / \mathrm{Bim}^{-1-}$ and $\mathrm{p} 53^{-1-} / \mathrm{Bid}^{-1-} / \mathrm{Bim}^{-1-}$ (triple knockout, TKO) bone marrow cells were expanded in culture in the presence of IL3, IL6 and SCF. The Bid/Bim-deficient cells (Supplementary Figure 3) underwent apoptosis with the same kinetics and to the same degree as the $\mathrm{Bim}^{-/}$cells (Figures 2a and b) in response to cytokine withdrawal alone or in combination with IR, excluding a role for Bid in the response to these death stimuli. In support of this observation, truncated Bid was not detected under these culture conditions (data not shown). The p53/Bid/Bim TKO primary myeloid cells were highly resistant to cytokine deprivation with or without IR, presumably due to the loss of Bim, p53 and indirectly Puma, which compromises the growth factor withdrawal- and DNA damage-induced apoptotic responses, respectively (Supplementary Figure 3 ). Together, these results demonstrate that the loss of p53 and Bim is sufficient to inhibit programmed cell death in these models of limiting cytokines and genotoxic stress.

Selective reduction of $\mathrm{Bcl}-\mathrm{X}_{\mathrm{L}}$ and $\mathrm{Mcl}-1$ during cytokine starvation. To further define the biochemical mechanisms controlling apoptosis, the expression of pro-survival and proapoptotic Bcl-2 family members in WT, Bim ${ }^{-\prime}, \mathrm{Puma}^{-/}$and Puma $^{-1-} / \mathrm{Bim}^{-/}$primary CTMCs was examined during cytokine starvation with and without DNA damage. Western blot analysis demonstrated that cytokine deprivation resulted in the reduction of $\mathrm{Bcl}-\mathrm{X}_{\mathrm{L}}$ and $\mathrm{Mcl}-1$ protein in each of the genetically altered cell lines (Figure 3 ). The decrease in Bcl$\mathrm{X}_{\mathrm{L}}$ and Mcl-1 expression is not a consequence of apoptosis per se, since the samples were harvested at early time points before cell death and occurred in fully viable $\mathrm{Puma}^{-1-} \mathrm{Bim}^{-1-}$ cells. The lower levels of $\mathrm{Bcl}-\mathrm{X}_{\mathrm{L}}$ and $\mathrm{Mcl}-1$, in response to cytokine deprivation, presumably sensitize cells to apoptosis.

Puma or Bim is required for the activation of Bax, MOMP and cytochrome $c$ release. Essential to programmed cell death is the activation of Bax and Bak to induce MOMP and cytochrome $c$ release. Therefore, the level of Bax activation was determined as a surrogate marker of early apoptosis in WT, Bim ${ }^{-1-}$, Puma ${ }^{-1-}$ and Puma ${ }^{-1-} / \mathrm{Bim}^{-/-}$primary CTMCs that were deprived of cytokines and/or subjected to IR at $16 \mathrm{~h}$ after treatment. Samples were subjected to immunoprecipitation using antibody $6 \mathrm{~A} 7$, which is specific for the conformation-altered form of activated Bax, followed by western blot analysis (Figure 4a). WT, $\mathrm{Bim}^{-/-}$and Puma $^{-1}$ cells that were deprived of cytokine (lane 2) and co-treated with IR (lane 4) exhibited a marked increase in activated Bax compared with untreated control cells (lane 1). DNA damage alone inhibited proliferation (Figure 2c) without 


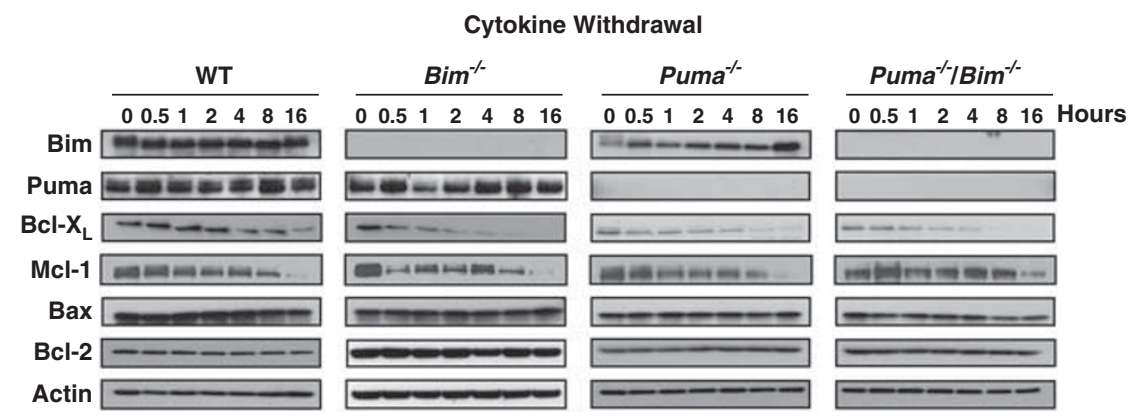

Figure 3 Cytokine withdrawal modulates the expression of both pro- and anti-apoptotic Bcl-2 family members in myeloid cells. WT, Bim ${ }^{-/}$, Puma $^{-/-}$and $P u m a^{-/-}$, $\mathrm{Bim}^{-/-}$cells were deprived of cytokines for $0-16 \mathrm{~h}$ and Bcl-2-related proteins were evaluated by western blot analysis. Representative blot from at least three independent experiments is presented

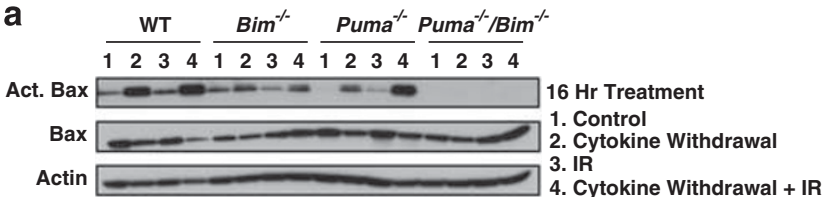

b

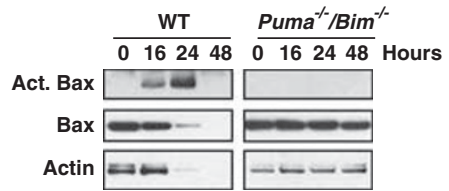

Figure 4 Bim and Puma are required for Bax activation in response to p53dependent and p53-independent cell death. (a) WT, $\mathrm{Bim}^{-1-}$, Puma $^{-1-}$ and Puma ${ }^{-1}$ $-/ \mathrm{Bim}^{-1-}$ primary CTMCs were deprived of cytokines for $16 \mathrm{~h}$ with or without $5 \mathrm{~Gy}$ IR. Bax activation was determined by immunoprecipitation with antibody $6 \mathrm{A7}$, which detects Bax in its active confirmation, and subsequent western blot analysis. Actin levels were assessed in cell lysates before immunoprecipitation $(n=2)$. (b) Western blot analysis of activated Bax in WT and Puma ${ }^{-1-} / \mathrm{Bim}^{-/-}$cells treated with cytokine withdrawal and 5 Gy IR for the indicated times $(n=2)$

significantly activating Bax (Figure 4a, lane 3 and data not shown). The degree of Bax activation corresponded to the level of cytochrome $c$ release from the mitochondria (data not shown) and the extent of cell death (Figures $2 a$ and $b$ ). Importantly, cytokine starvation with and without IR failed to activate Bax in the Puma/Bim DKO cells, which maintained mitochondrial integrity as determined by cytochrome $c$ retention and cell viability (Figures $2 a$ and $b$ and data not shown).

The kinetics of Bax activation during cytokine withdrawal plus IR was also determined (Figure 4b). Treatment of WT cells resulted in significant Bax activation by $24 \mathrm{~h}$, coinciding with rampant apoptosis (Figure 2b) and loss of intact Actin protein. By contrast, the Puma ${ }^{-/-} / \mathrm{Bim}^{-/-}$cells were completely devoid of activated Bax and remained fully viable following cytokine withdrawal and IR (Figure 2b). Therefore, either Puma or Bim is sufficient for the activation of Bax, MOMP and apoptosis in primary CTMCs deprived of cytokine and treated with IR.

Requirement for Puma or Bim in Bax activation and apoptosis during ABT-737 treatment. The neutralization model proposes that the anti-apoptotic $\mathrm{Bcl}-2$ proteins bind and sequester Bax and Bak, preventing its activation and hence apoptosis. ${ }^{20,21}$ Therefore, inhibition of $\mathrm{Bcl}-2$ and $\mathrm{BCl}-\mathrm{X}_{\mathrm{L}}$ with the $\mathrm{BH} 3-$ mimetic $\mathrm{ABT}-737$ should permit efficient Bax activation and cell death in the absence of Bim and Puma, analogous to WT cells. To test this hypothesis, WT, Bim ${ }^{-/-}$, Puma ${ }^{-/-}$and Puma $^{-/-} / \mathrm{Bim}^{-/-}$ primary CTMCs were treated with either ABT-737 $(1 \mu \mathrm{M})$ alone or in combination with cytokine withdrawal, and assayed for apoptosis by flow cytometry (Figure 5). WT and $\mathrm{Bim}^{-/-}$cells treated with ABT-737 in the presence of cytokines displayed a modest induction of apoptosis, whereas Puma/Bim DKO cells were completely resistant (Figure 6a, left panel: $P \leq 0.026$ ). Despite the induction of extensive apoptosis of WT, Bim ${ }^{-/}$and Puma $^{-/-}$cells during cytokine withdrawal plus ABT-737 treatment, the Puma ${ }^{-/-} /$ $\mathrm{Bim}^{-/-}$primary cells remained fully viable similar to $\mathrm{Bax}^{-/-}$ $\mathrm{Bak}^{-1-}$ cells (Figure 5a, middle panel: $P \leq 0.036$ ). By contrast, cells only deprived of cytokines for $16 \mathrm{~h}$ maintained substantial viability, demonstrating the efficacy of ABT-737 (Figure 5a, right panel versus middle panel). Consistent with these results, Bax activation was rapid and robust in WT and $\mathrm{Bim}^{-/-}$cells, slightly delayed in Puma ${ }^{-/-}$ cells and absent in Puma ${ }^{-1-} / \mathrm{Bim}^{-1-}$ cells deprived of cytokines and treated with ABT-737 (Figure 5c). Therefore, the diminished expression of $\mathrm{Bcl}-2$ survival proteins during cytokine withdrawal (Figure 3) in combination with ABT-737 to further antagonize $\mathrm{Bcl}-2$ and $\mathrm{Bcl}-\mathrm{X}_{\mathrm{L}}$ function is not sufficient to activate Bax/Bak nor to induce apoptosis in Puma $^{-/-} / \mathrm{Bim}^{-/-}$cells. Finally, the extent of apoptosis at $48 \mathrm{~h}$ in primary CTMCs lacking Bid, Bim and p53 during cytokine withdrawal plus ABT-737 is indistinguishable from WT cells (Figures $5 \mathrm{a}$ and $\mathrm{b}$, middle panels). These findings establish Puma as an essential activator of Bax/Bak and cell death even in the absence of all other reported direct activators.

ABT-737 induced MOMP during growth factor withdrawal requires Puma and Bim. The biochemical roles of Puma and Bim and the effect of ABT-737 on MOMP were assessed in WT, Puma ${ }^{-/} / \mathrm{Bim}^{-/-}$and $\mathrm{Bax}^{-/-} /$ $\mathrm{Bak}^{-1-}$ primary CTMCs deprived of cytokines for $6 \mathrm{~h}$. Cells were then permeabilized with digitonin and incubated with Bim, Puma or a non-specific peptide, caspase-8 cleaved Bid 


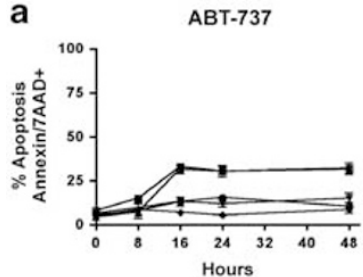

b

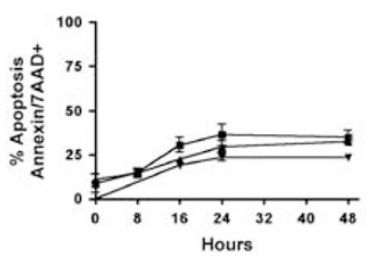

Cytokine Withdrawal + ABT-737

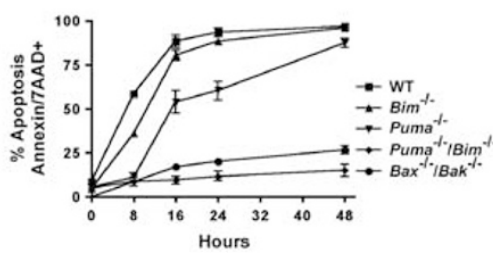

Cytokine Withdrawal + ABT-737
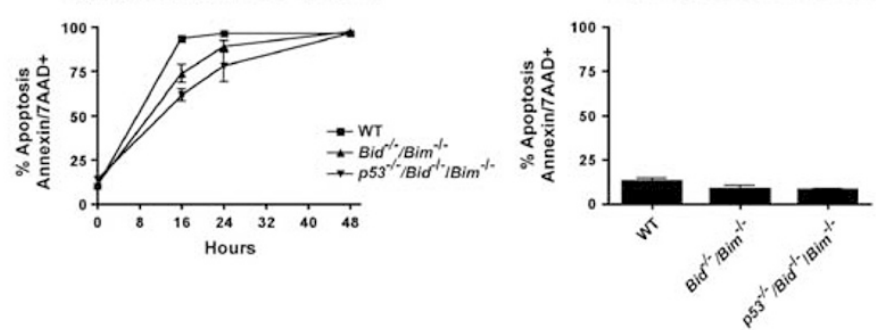

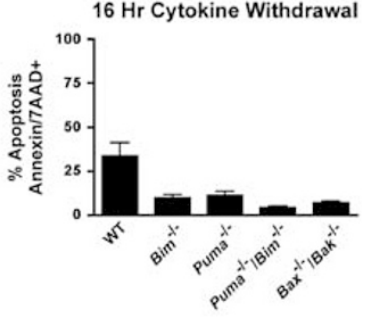

$16 \mathrm{Hr}$ Cytokine Withdrawa

C

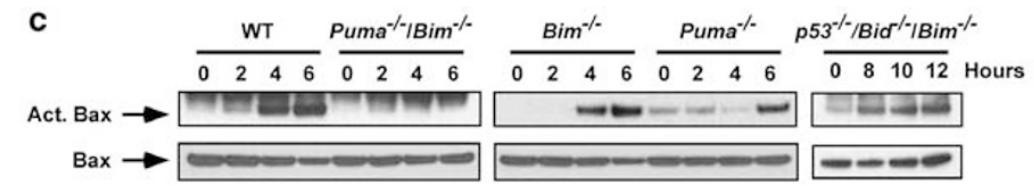

Figure 5 Bax activation and apoptosis in response to Bcl-2 and Bcl- $\mathrm{X}_{\mathrm{L}}$ inhibition is dependent upon Bim and Puma. (a) WT, Bim ${ }^{-/}$, Puma $^{-/-}$or Puma ${ }^{-/-} / \mathrm{Bim}^{-/}$ primary CTMCs were treated with $1 \mu \mathrm{M}$ ABT-737 for the indicated times in fully supplemented media (left panel) and under conditions of cytokine withdrawal (middle panel), or treated with cytokine withdrawal alone for $16 \mathrm{~h}$ (right panel). Apoptosis was determined by flow cytometric evaluation of AnnexinV/7AAD-positive population. (b) WT, Bim ${ }^{-/-}$/

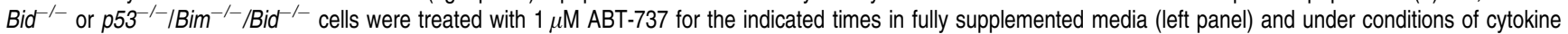
withdrawal (middle panel) or treated with cytokine withdrawal alone for $16 \mathrm{~h}$ (right panel). (c) IP/western blot analysis of Bax activation in cells deprived of cytokines and treated with ABT-737 as described in Materials and Methods $(n=2)$. Data in $(\mathbf{a}$ and $\mathbf{b})$ are presented as the mean \pm S.E.M. of three independent experiments

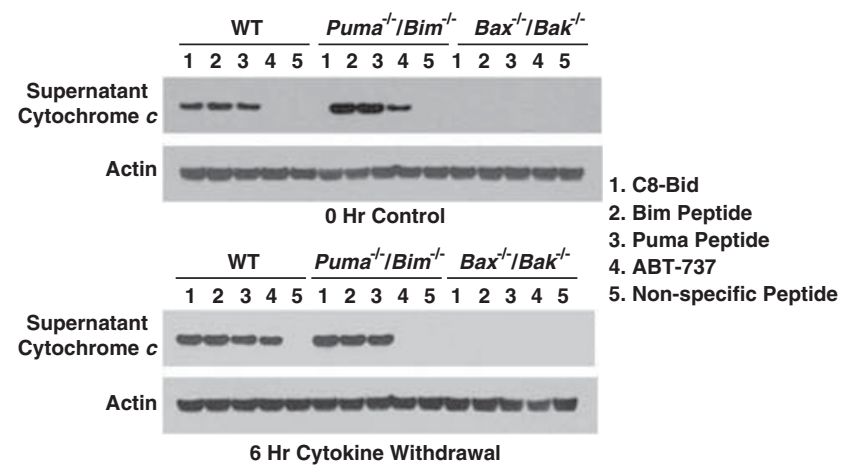

Figure 6 ABT-737 induced cytochrome $c$ release is Bim and Puma dependent. Primary WT, Puma ${ }^{-1-} / \mathrm{Bim}^{-1-}$ and $\mathrm{Bax}^{-1-} / \mathrm{Bak}^{-1-}$ CTMCs were cultured in the presence or absence of cytokines for $6 \mathrm{~h}$, permeablized in $0.015 \%$ digitonin and treated with C8-Bid (25 nM), Puma or Bim peptide $(10 \mu \mathrm{M})$ or ABT-737 $(0.75 \mu \mathrm{M})$ for $75 \mathrm{~min}$. Cytochrome $c$ release was determined by western blot analysis and actin was used as a loading control. Representative blot from three independent experiments is presented

or ABT-737 and supernatants were collected after centrifugation. The presence of cytochrome $c$ in the supernatant was then assayed by western blot as an indicator of MOMP (Figure 6). Primary cells maintained in the presence of cytokines served as controls. Regardless of the culture conditions, WT and $\mathrm{Puma}^{-1-} / \mathrm{Bim}^{-1-}$ CTMCs incubated with either Puma or Bim peptides released cytochrome $c$ from the mitochondria, while the $\mathrm{Bax}^{-/} /$ $\mathrm{Bak}^{-1-}$ cells were fully resistant. Importantly, the BH3-mimetic ABT-737 induced MOMP in WT, but not Puma $^{-1-} / \mathrm{Bim}^{-1-}$ or Bax/Bak DKO cells deprived of cytokines. These results suggest that cytokine starvation sensitizes cells to MOMP primarily through Bim and/or Puma in a Bax/Bak-dependent manner.

\section{Discussion}

We addressed the physiological functions of Puma and Bim and the mechanisms by which they induce cell death using genetically engineered mouse models. Previous studies examining the loss of Puma, Bim or in combination have demonstrated that these proteins are mostly redundant in the context of growth factor withdrawal or glucocorticoid treatment in mast, T and B cells. ${ }^{14,22}$ However, our results clearly demonstrate that $\mathrm{Bim}^{-1-}$ and Puma ${ }^{-1-}$ mice respond differently to carboplatin and IR-induced lethal myelosuppression. Puma knockouts were highly resistant to both Gl syndrome and hematopoietic failure with $100 \%$ of the animals surviving past 30 days, whereas WT and Bim-deficient mice displayed marked hyperplasia in the colon with systemic bacteremia, in combination with a failure to recover hematopoiesis and died within 2 weeks of treatment (Figure 1). In support of this finding, two independent studies demonstrated that the loss of 
Puma conferred a similar survival advantage during high-dose IR due to hematopoietic stem cell protection. ${ }^{23,24}$ However, as we show here, deletion of both Puma and Bim was required for long-term survival, suggesting that each may have a defined role in hematopoietic stem and/or progenitor cells.

Cytokine signaling pathways maintain elevated levels of $\mathrm{Bcl}-2, \mathrm{Bcl}-\mathrm{X}_{\mathrm{L}}$ and $\mathrm{Mcl}-1$, while limiting the expression of Puma, Bim and other pro-apoptotics. Therefore, cytokine withdrawal sensitizes primary cells to apoptosis by altering the balance between pro-survival and pro-apoptotic proteins. Puma ${ }^{-1-}$ $\mathrm{Bim}^{-1-}$ cells deprived of cytokines express lower levels of Bcl$\mathrm{X}_{\mathrm{L}}$ and $\mathrm{Mcl}-1$, but maintain viability, demonstrating that the decrease in $\mathrm{Bcl}-\mathrm{X}_{\mathrm{L}}$ and $\mathrm{Mcl}-1$ occurs independently of binding to Bim or Puma, and cell death (Figures 2 and 3). Primary CTMCs deprived of cytokines and treated with IR undergo p53-dependent apoptosis. Although deletion of Bim or Puma conferred only partial protection, $\mathrm{Puma}^{-/} / \mathrm{Bim}^{-/-}$cells were completely resistant to cytokine starvation and IR due to a failure to activate Bax and MOMP (Figure 4 and data not shown). The DKO cells remain completely viable, but undergo cell-cycle arrest and efficiently resume DNA synthesis when restimulated with cytokines (Figure 2c). Consistent with these results, recombinant TPO, or the deletion of either p53 or Puma, fully protects mice from a lethal myelosuppressive regimen of carboplatin and IR (Figure 1). ${ }^{11}$ These findings establish a clinically relevant link between cytokines, DNA damage and p53 signaling pathways.

The p53 tumor suppressor induces apoptosis through the transcriptional induction of downstream target genes, such as Puma, Noxa and Bax. ${ }^{25}$ It has also been proposed that p53 directly activates Bax and this transcription-independent proapoptotic activity is inhibited by binding to $\mathrm{Bcl}-2, \mathrm{Bcl}-\mathrm{X}_{\mathrm{L}}$ and Mcl-1. ${ }^{7-9}$ In this model, the induction of Puma during cellular stress competitively binds $\mathrm{Bcl}-\mathrm{X}_{\mathrm{L}}$, which free p53 to activate Bax and trigger apoptosis. ${ }^{9}$ As shown in Figure $5 \mathrm{~b}$, TKO primary CTMCs deficient in Bid, Bim and p53 underwent apoptosis to the same extent as WT cells when deprived of cytokines and treated with ABT-737, demonstrating that these three putative direct activators of Bax are dispensable for cell death under these conditions. In light of these results and the findings that Puma/Bim DKO cells are completely resistant to cytokine starvation plus ABT-737 (Figure 5a), we propose that endogenous Puma is sufficient to activate Bax in vivo (Figure 5c). In support of this conclusion, recent studies have reported a direct interaction between Puma with Bax in cellfree systems and yeast. ${ }^{26,27}$

Puma $^{-/-} /$Bim $^{-/-}$primary CTMCs provided a unique opportunity to challenge the 'direct activator/derepressor' versus 'neutralization' models of Bax activation utilizing the $\mathrm{BH}$ mimetic drug ABT-737. ${ }^{19}$ We hypothesized that if the neutralization model was operative, then treatment of Puma $^{-1-} / \mathrm{Bim}^{-1-}$ cells with ABT-737 in the absence of cytokines should induce apoptosis by releasing Bax and Bak from sequestration by the anti-apoptotic Bcl-2 family members. Although $\mathrm{Mcl}-1$ protects cells from apoptosis mediated by $\mathrm{ABT}-737,{ }^{28-30}$ our data demonstrate that the expression of this anti-apoptotic protein is markedly diminished upon cytokine withdrawal. Furthermore, WT cells deprived of cytokines and treated with ABT-737 rapidly underwent apoptosis, suggesting that $\mathrm{Mcl}-1$ and other survival factors, such as A1, are not sufficient to block MOMP and cell death. By contrast, Puma ${ }^{-/-} / \mathrm{Bim}^{-/-}$cells were completely protected from Bax activation and apoptosis, demonstrating an essential role for Bim and Puma in triggering cell death. Our findings provide genetic and biochemical evidence in support of the direct activator/derepressor model of apoptosis. ${ }^{19-21}$ Similar results and conclusions have been generated using $\mathrm{Bid}^{-/} /$Bim $^{-1-} /$ Puma $^{-1-}$ TKO mice and primary cells. ${ }^{31}$

Puma expression is naturally selected against during lymphomagenesis in $\mathrm{c}-M y c$ transgenic mice and primary human Burkitt lymphomas. ${ }^{32,33}$ Therefore, restoring Puma apoptotic function would be a reasonable goal for treating specific malignancies, and BH3 mimetics (e.g. ABT-737, SAHBs) could provide such an opportunity. ${ }^{26,34}$ Interestingly, Strasser and Villunger recently reported the surprising findings that Puma deficiency suppresses lymphomagenesis in response to low-dose, fractionated ionizing radiation, raising the cautionary flag that $\mathrm{BH} 3$ mimetics could promote secondary malignancies in the context of cancer therapies. ${ }^{35,36}$ Our studies complement these findings and show that Puma deficiency also protects against a lethal dose of carboplatin and ionizing radiation without increasing tumor susceptibility.

In summary, we demonstrated that Puma and Bim cooperate in activating Bax, MOMP and apoptosis both in vitro and in vivo in response to cell stress. We also provided mechanistic insight into how these pro-apoptotic BH3-only proteins trigger cell death, supporting the 'direct activator' of apoptosis model. Most importantly, we identified Puma and Bim as key targets that limit chemo and radiation therapy due to Gl syndrome and bone marrow toxicity. These findings provide a proof-of-principle that $\mathrm{BH} 3$ antagonists, such as small molecule inhibitors, could be developed to protect hematopoiesis and the GI tract from DNA damaging agents commonly used in cancer treatments without significantly increasing susceptibility to secondary malignancies. Given the scope of Puma in other pathological diseases, such as heart ischemia, stroke and neurodegeneration, the application of $\mathrm{BH} 3$ antagonists could have broader clinical implications.

\section{Materials and Methods}

Reagents. Caspase-8 cleaved mouse BID (C8-BID; R\&D Systems, Minneapolis, MN, USA), anti-cytochrome $c$ (clone 7H8.2C12, BD Pharmingen, San Jose, CA, USA), anti-BAK (clone NT, Millipore, Billerica, MA, USA), anti-Mcl-1 (Rockland, Gilbertsville, PA, USA), anti-Bcl- $\mathrm{X}_{\mathrm{L}}$ (clone 4) and anti-Bcl-2 (clone 7; both from BD Transduction Laboratories, San Diego, CA, USA), anti-Bax (N-20) and antiBim (H-191) were from Santa Cruz Biotechnology (La Jolla, CA, USA), anti-Bax (clone 6A7) anti-Puma (N-terminus) and anti- $\beta$-actin (clone AC-15, Sigma-Aldrich, St. Louis, MO, USA). ABT-737 was a gift from Dr. Stephen Fesik, Abbott Laboratories (Abbott Park, IL, USA). BH3 domain peptides, Bim, and PUMA, sequences as described. ${ }^{37}$ Peptides were resuspended in anhydrous DMSO, stored at $-80^{\circ} \mathrm{C}$, and thawed only once.

Animals. Puma ${ }^{-/-}$(C57BL6/SV129 mixed) mice were previously reported. ${ }^{15}$ $\mathrm{Bim}^{-1-}$ (C57BL6/SV129 mixed) mice were a kind gift from Andreas Strasser (WEHI) and have been reported elsewhere. ${ }^{38} \mathrm{The} \mathrm{Bid}^{-/-}$(C57BL6/SV129 mixed) and conditional Bax/Bak knockout mice were generously provided by Stanley Korsmeyer and have been reported elsewhere. ${ }^{39,40} \mathrm{Puma}^{+/-}$and $\mathrm{Bim}^{+/-}$mice (C57BL6/SV129 mixed) were intercrossed to generate Puma $^{-/-} / \mathrm{Bim}^{-/-}$(DKO) littermates. $p 53^{-1-}$ (C57/BL6) mice were obtained from The Jackson Laboratory (Bar Harbor, ME, USA). Bid ${ }^{-1} / \mathrm{Bim}^{-1-}$ (C57BL6/SV129) mice have been reported 


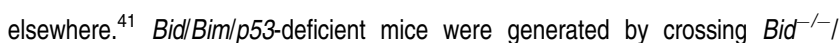
$\mathrm{Bim}^{-/}$and $\mathrm{p} 53^{-/-}$animals. Resulting progeny was intercrossed to obtain (C57BL6/SV129) TKO mice. All animal procedures were approved by the St. Jude Children's Research Hospital Institutional Animal Care and Use Committee.

Myelosuppressive regimen. Mice were given $80 \mathrm{mg} / \mathrm{kg}$ carboplatin (SICOR Pharmaceuticals, Inc., Irvine, CA, USA) intravenously immediately followed by 7.5 Gy total body ionizing radiation for the indicated period while on the antibiotic Baytril. ${ }^{11}$ All mice were observed daily for signs of morbidity and tumor development. Tissues from morbid or moribund mice were fixed in $4 \%$ paraformaldehyde for subsequent histopathological evaluation.

Blood counts. Blood was collected into EDTA-coated 20 I microcapillary tubes (Fisher Scientific, Pittsburgh, PA, USA). WBC counts, hemoglobin concentration and platelet counts were determined using a FORCYTE Hematology System (Oxford Science, Inc., Oxford, CT, USA).

Bone marrow-derived primary myeloid cell isolation, culture and treatment. Bone marrow was isolated from the hind femur and tibias of WT, $\mathrm{Bim}^{-1-}$, Puma ${ }^{-/-}$and Puma ${ }^{-/} / \mathrm{Bim}^{-/-}$mice. Primary myeloid cells were consequently generated as described elsewhere and cultured in RMPI-1640 supplemented with $15 \% \mathrm{FBS}, 1 \% \mathrm{P} / \mathrm{S}, 10 \mathrm{mM}$ glutamine, $10 \mathrm{ng} / \mathrm{ml}$ mouse recombinant SCF (R\&D), $10 \mathrm{ng} / \mathrm{ml}$ mouse recombinant IL-6 (R\&D) and $40 \mathrm{U} / \mathrm{ml}$ mouse recombinant IL-3. ${ }^{15,16}$ Following 3 weeks of culture with regular changes of media, the immunophenotype was determined by flow cytometry. Established homogenous cultures of bone marrow-derived cells were Sca- $1^{+} \mathrm{CKit}^{+}$, negative for F4/80, GR-1/Ly6G, CD4, CD8, B220 and Ter-119 and positive for FcR1. Primary CTMCs were washed twice with HBSS and resuspended in cytokine-free media before IR (5 Gy) exposure or ABT-737 $(1 \mu \mathrm{M})$. Cells were incubated for indicated time periods and cell responses compared with cells cultured in the presence of cytokines.

Cell viability and apoptosis determination. Cell concentration and viability was evaluated by trypan blue exclusion utilizing a Vi-CELL automated analyzer (Beckman Coulter, Brea, CA, USA). Apoptosis was determined by flow cytometric evaluation of the AnnexinV-positive population. Samples were washed twice with ice-cold PBS and stained with AnnexinV-APC and 7-AAD according to the manufacturer's instructions (BD Biosciences, San Jose, CA, USA).

Protein isolation and western blot analysis. Cells were harvested, washed in PBS and resuspended in CHAPS buffer ( $1 \%$ CHAPS, 10 mM HEPES, pH $7.4,150 \mathrm{mM} \mathrm{NaCl}$ ) containing Complete Mini protease inhibitor pill (Roche, Applied Science, Indianapolis, IN, USA), phosphatase inhibitors and $1 \mu \mathrm{M}$ PMSF (SigmaAldrich). The lysates were incubated on ice for $30 \mathrm{~min}$ and supernatants harvested following centrifugation at $13000 \times g$ for $15 \mathrm{~min}$. Protein concentrations were determined by the BCA assay (Thermo Scientific, Rockford, IL, USA) as described by the manufacturer's instructions. Protein expression $(50 \mu \mathrm{g} /$ lane for both cellular and isolated mitochondria experiments) was determined by SDS-polyacrylamide gel electrophoresis (PAGE) and subsequent western blot analysis (Invitrogen, Carlsbad, CA, USA). Western blot filters were probed with the indicated primary antibodies followed by horseradish peroxidase-conjugated secondary antibodies (KPL, Inc., Gaithersburg, MD, USA). Proteins were visualized using the enhanced chemiluminescence (ECL) system (Thermo Scientific) followed by exposure to CL-Xposure films (Kodak, Rochester, NY, USA).

Immunoprecipitation of activated Bax. To detect the active form of Bax, primary CTMCs were collected and lysed in CHAPS lysis buffer on ice. Briefly, activated Bax was immunoprecipitated from $500 \mu \mathrm{g}$ of whole cell lysates with the monoclonal antibody clone 6A7 (Sigma-Aldrich), which reacts only with Bax in its conformationally active state, and Protein G Sepharose 4 Fast Flow Beads (Amersham, Little Chalfont, UK). Isolated active Bax samples were then subjected to western blot analysis and identified with a rabbit polyclonal anti-Bax (N-20; Santa Cruz Biotechnology) antibody and ECL as described above.

Cellular permeablization and MOMP analysis. Primary CTMCs $\left(5 \times 10^{6} /\right.$ sample) were collected, washed in PBS and incubated on ice for $5 \mathrm{~min}$ in permeability buffer ( $20 \mathrm{mM} \mathrm{HEPES}, \mathrm{pH} 7.2,100 \mathrm{mM} \mathrm{KCl}, 5 \mathrm{mM} \mathrm{MgCl}, 1 \mathrm{mM}$ EDTA, $1 \mathrm{mM}$ EGTA, $250 \mathrm{mM}$ sucrose and $0.015 \%$ digitonin from $10 \%$ DMSO stock) containing Complete Mini protease inhibitor pill. Proteins, peptides and ABT-737 (final concentrations indicated in the figure legends) were then added and the cells were incubated at $30^{\circ} \mathrm{C}$ for $1.25 \mathrm{~h}$. Samples were centrifuged for $10 \mathrm{~min}$ in $4^{\circ} \mathrm{C}$ at $15000 \times g$. Supernatants were collected and analyzed by SDS-PAGE and western blot with anti-cytochrome $c$ (clone $7 \mathrm{H} 8.2 \mathrm{C} 12)$.

BrdU incorporation. Primary myeloid cells were labeled with $10 \mu \mathrm{M}$ 5-bromo$2^{\prime}$-deoxy-uridine (BrdU) for $24 \mathrm{~h}$ at $37^{\circ} \mathrm{C}$ under aseptic conditions. Cells were harvested and BrdU incorporation was determined using the 'APC BrdU Flow Kit' according to the manufacturer's instructions using a FACScalibur flow cytometer (BD Biosciences).

\section{Conflict of Interest}

The authors declare no conflict of interest.

Acknowledgements. We thank Dr. Carl Jackson for his advice regarding the myelosuppressive regimen in mouse models. We thank the Hartwell Center and Flow Cytometry \& Cell Sorting Facility at St. Jude Children's Research Hospital for their technical assistance. This work was supported in part by $\mathrm{NIH}$ grants and $\mathrm{NIH} /$ $\mathrm{NCl}$ Cancer Center Support CORE Grant CA21765. We are also grateful to the American Lebanese Syrian Associated Charities (ALSAC) of St. Jude Children's Research Hospital for their generous support.

1. Thompson CB. Apoptosis in the pathogenesis and treatment of disease. Science 1995; 267: 1456-1462.

2. Chipuk JE, Green DR. PUMA cooperates with direct activator proteins to promote mitochondrial outer membrane permeabilization and apoptosis. Cell Cycle 2009; 8: 2692-2696

3. Oberst $A$, Bender $C$, Green DR. Living with death: the evolution of the mitochondrial pathway of apoptosis in animals. Cell Death Differ 2008; 15: 1139-1146.

4. Willis SN, Adams JM. Life in the balance: how BH3-only proteins induce apoptosis. Curr Opin Cell Biol 2005; 17: 617-625.

5. Youle RJ, Strasser A. The BCL-2 protein family: opposing activities that mediate cell death. Nat Rev Mol Cell Biol 2008; 9: 47-59.

6. Letai A, Bassik MC, Walensky LD, Sorcinelli MD, Weiler S, Korsmeyer SJ. Distinct BH3 domains either sensitize or activate mitochondrial apoptosis, serving as prototype cancer therapeutics. Cancer Cell 2002; 2: 183-192.

7. Mihara M, Erster S, Zaika A, Petrenko O, Chittenden T, Pancoska P et al. p53 has a direct apoptogenic role at the mitochondria. Mol Cell 2003; 11: 577-590.

8. Leu JI, Dumont P, Hafey M, Murphy ME, George DL. Mitochondrial p53 activates Bak and causes disruption of a Bak-Mcl1 complex. Nat Cell Biol 2004; 6: 443-450.

9. Chipuk JE, Kuwana T, Bouchier-Hayes L, Droin NM, Newmeyer DD, Schuler M et al. Direct activation of Bax by 553 mediates mitochondrial membrane permeabilization and apoptosis. Science 2004; 303: 1010-1014.

10. Kim H, Rafiuddin-Shah M, Tu HC, Jeffers JR, Zambetti GP, Hsieh JJ et al. Hierarchical regulation of mitochondrion-dependent apoptosis by BCL-2 subfamilies. Nat Cell Biol 2006; 8: 1348-1358.

11. Pestina TI, Cleveland JL, Yang C, Zambetti GP, Jackson CW. Mpl ligand prevents lethal myelosuppression by inhibiting p53-dependent apoptosis. Blood 2001; 98: 2084-2090.

12. Packham G, White EL, Eischen CM, Yang H, Parganas E, Ihle JN et al. Selective regulation of $\mathrm{BCl}-\mathrm{XL}$ by a Jak kinase-dependent pathway is bypassed in murine hematopoietic malignancies. Genes Dev 1998; 12: 2475-2487.

13. Quelle FW, Wang J, Feng J, Wang D, Cleveland JL, Ihle JN et al. Cytokine rescue of p53dependent apoptosis and cell cycle arrest is mediated by distinct Jak kinase signaling pathways. Genes Dev 1998; 12: 1099-1107.

14. Erlacher M, Labi V, Manzl C, Bock G, Tzankov A, Hacker G et al. Puma cooperates with $\mathrm{Bim}$, the rate-limiting BH3-only protein in cell death during lymphocyte development, in apoptosis induction. J Exp Med 2006; 203: 2939-2951.

15. Jeffers JR, Parganas E, Lee $Y$, Yang C, Wang J, Brennan J et al. Puma is an essential mediator of p53-dependent and -independent apoptotic pathways. Cancer Cell 2003; 4: 321-328.

16. Phillips DC, Garrison SP, Jeffers JR, Zambetti GP. Assays to measure p53-dependent and -independent apoptosis. Methods Mol Biol 2009; 559: 143-159.

17. Ekoff M, Strasser A, Nilsson G. FcepsilonRI aggregation promotes survival of connective tissue-like mast cells but not mucosal-like mast cells. J Immunol 2007; 178: 4177-4183.

18. Canman CE, Gilmer TM, Coutts SB, Kastan MB. Growth factor modulation of p53mediated growth arrest versus apoptosis. Genes Dev 1995; 9: 600-611.

19. Chipuk JE, Moldoveanu T, Llambi F, Parsons MJ, Green DR. The BCL-2 family reunion. Mol Cell 2010; 37: 299-310.

20. Uren RT, Dewson G, Chen L, Coyne SC, Huang DC, Adams JM et al. Mitochondrial permeabilization relies on $\mathrm{BH} 3$ ligands engaging multiple prosurvival $\mathrm{Bcl}-2$ relatives, not Bak. J Cell Biol 2007; 177: 277-287. 
21. Willis SN, Fletcher Jl, Kaufmann T, van Delft MF, Chen L, Czabotar PE et al. Apoptosis initiated when BH3 ligands engage multiple Bcl-2 homologs, not Bax or Bak. Science 2007; 315: 856-859.

22. Ekoff M, Kaufmann T, Engstrom M, Motoyama N, Villunger A, Jonsson Jl et al. The BH3only protein Puma plays an essential role in cytokine deprivation induced apoptosis of mas cells. Blood 2007; 110: 3209-3217.

23. Yu H, Shen H, Yuan Y, XuFeng R, Hu X, Garrison SP et al. Deletion of Puma protects hematopoietic stem cells and confers long-term survival in response to high-dose gammairradiation. Blood 2010; 115: 3472-3480.

24. Shao L, Sun Y, Zhang Z, Feng W, Gao Y, Cai Z et al. Deletion of proapoptotic Puma selectively protects hematopoietic stem and progenitor cells against high-dose radiation. Blood 2010; 115: 4707-4714.

25. Vousden KH, Prives C. Blinded by the light: the growing complexity of p53. Cell 2009; 137 413-431.

26. Gavathiotis E, Suzuki M, Davis ML, Pitter K, Bird GH, Katz SG et al. BAX activation is initiated at a novel interaction site. Nature 2008; 455: 1076-1081.

27. Gallenne T, Gautier F, Oliver L, Hervouet E, Noel B, Hickman JA et al. Bax activation by the $\mathrm{BH} 3-$ only protein Puma promotes cell dependence on antiapoptotic Bcl-2 family members. J Cell Biol 2009; 185: 279-290.

28. Tahir SK, Yang X, Anderson MG, Morgan-Lappe SE, Sarthy AV, Chen J et al. Influence of $\mathrm{Bcl}-2$ family members on the cellular response of small-cell lung cancer cell lines to ABT-737. Cancer Res 2007; 67: 1176-1183.

29. Whitecross KF, Alsop AE, Cluse LA, Wiegmans A, Banks KM, Coomans $C$ et al. Defining the target specificity of ABT-737 and synergistic antitumor activities in combination with histone deacetylase inhibitors. Blood 2009; 113: 1982-1991.

30. van Delft MF, Wei AH, Mason KD, Vandenberg CJ, Chen L, Czabotar PE et al. The BH3 mimetic ATBT-737 targets selective $\mathrm{Bcl}-2$ proteins and efficiently induces apoptosis via Bax/Bak if Mcl-1 is neutralized. Cancer Cell 2006; 10: 389-399.

31. Ren D, Tu HC, Kim H, Wang GX, Bean GR, Takeuchi O et al. BID, BIM, and PUMA are essential for activation of the BAX- and BAK-dependent cell death program. Science 2010; 330: $1390-1393$.
32. Garrison SP, Jeffers JR, Yang C, Nilsson JA, Hall MA, Rehg JE et al. Selection against PUMA gene expression in Myc-driven B-cell lymphomagenesis. Mol Cell Biol 2008; 28: 5391-5402.

33. Michalak EM, Jansen ES, Happo L, Cragg MS, Tai L, Smyth GK et al. Puma and to a lesser extent Noxa are suppressors of Myc-induced lymphomagenesis. Cell Death Differ 2009; 16: 684-696.

34. Oltersdorf T, Elmore SW, Shoemaker AR, Armstrong RC, Augeri DJ, Belli BA et al. An inhibitor of Bcl-2 family proteins induces regression of solid tumours. Nature 2005; 435 : 677-681.

35. Michalak EM, Vandenberg CJ, Delbridge AR, Wu L, Scott CL, Adams JM et al. Apoptosispromoted tumorigenesis: gamma-irradiation-induced thymic lymphomagenesis requires Puma-driven leukocyte death. Genes Dev 2010; 24: 1608-1613.

36. Labi V, Erlacher M, Krumschnabel G, Manzl C, Tzankov A, Pinon J et al. Apoptosis of leukocytes triggered by acute DNA damage promotes lymphoma formation. Genes Dev 2010; 24: 1602-1607.

37. Kuwana T, Bouchier-Hayes L, Chipuk JE, Bonzon C, Sullivan BA, Green DR et al. $\mathrm{BH} 3$ domains of $\mathrm{BH} 3-$ only proteins differentially regulate Bax-mediated mitochondrial membrane permeabilization both directly and indirectly. Mol Cell 2005; 17 : 525-535.

38. Bouillet P, Metcalf D, Huang DC, Tarlinton DM, Kay TW, Kontgen F et al. Proapoptotic Bcl2 relative Bim required for certain apoptotic responses, leukocyte homeostasis, and to preclude autoimmunity. Science 1999; 286: 1735-1738.

39. Yin XM, Wang K, Gross A, Zhao Y, Zinkel S, Klocke B et al. Bid-deficient mice are resistant to Fas-induced hepatocellular apoptosis. Nature 1999; 400: 886-891.

40. Takeuchi O, Fisher J, Suh H, Harada H, Malynn BA, Korsmeyer SJ. Essential role of BAX, BAK in B cell homeostasis and prevention of autoimmune disease. Proc Natl Acad Sci USA 2005; 102: 11272-11277.

41. Chipuk JE, Fisher JC, Dillon CP, Kriwacki RW, Kuwana T, Green DR. Mechanism of apoptosis induction by inhibition of the anti-apoptotic BCL-2 proteins. Proc Natl Acad Sci USA 2008; 105: 20327-20332.

Supplementary Information accompanies the paper on Cell Death and Differentiation website (http://www.nature.com/cdd) 